\title{
Investigation of Repeatability of Sol-Gel Iridium Oxide pH Sensor on Flexible Substrate
}

\author{
Wen-Ding Huang, Lun-Chen Hsu, Jianqun Wang, Thermpon Ativanichayaphong, \\ Sanchali Deb, Mu Chiao* and J.C. Chiao \\ Department of Electrical Engineering, University of Texas at Arlington, TX, USA \\ *Department of Mechanical Engineering, University of British Columbia, Vancouver, BC, Canada
}

\begin{abstract}
In this paper, we presented the fabrication process of miniature $\mathrm{pH}$ sensor arrays on flexible polymer substrates. The repeatability of the sensors based on sol-gel fabrication processes was investigated. The sensor repeatability was characterized with linearity, decay time, environmental parameter control and potential stability. Similar linear responses were found in different batches of sensor arrays. Near superNernstian responses were measured on each sensor with slope ranges from -71.6 to $-110 \mathrm{mV} / \mathrm{pH}$ within a $\mathrm{pH}$ range between 2 and 12. The response times were compared in different batches. Six to twenty five seconds of average decay time were shown in each sample repeatedly. Three sensors showed the close potential response in different volumes of $\mathrm{pH}$ buffer solution. The sensor showed good stability in each step of the titration process between $\mathrm{pH}$ values of 1.8 and 11.9. The peak and saturated potential values presented high correlation with $\mathrm{pH}$ values with minor noises. The results showed good sensitivity, stability and repeatability using the sol-gel processes for iridium-oxide $\mathrm{pH}$ sensors on flexible substrates.
\end{abstract}

Key words: miniature $\mathrm{pH}$ sensor, sol-gel process, linearity, decay time, environmental parameter control, potential stability

\section{INTRODUCTION}

Although the glass membrane $\mathrm{pH}$ electrodes have been used in wide range of applications because of the good sensitivity, selectivity, stability and long lifetime [1], the fragility and physical size features of glass electrodes still restrict the applications on in vivo biomedical, clinical and food monitoring. To target at those applications, the different kinds of miniature $\mathrm{pH}$ sensor such as ion-sensitive field-effect transistor (iSFET) $\mathrm{pH}$ sensors [2,3], optical fiber $\mathrm{pH}$ sensors [4,5], hydrogel film $\mathrm{pH}$ sensors [6] and solid-sate $\mathrm{pH}$ sensors $[7,8]$ were investigated and demonstrated. However, most of those sensors were still built on rigid substrate such as silicon wafer or glass slide. The non-deformable $\mathrm{pH}$ sensors cannot be used for certain in vivo environment such as the neuronal implants [9,10]. Therefore, the polymer-based substrate [11] was chose and applied on the fabrication for the next generation $\mathrm{pH}$ sensor.

In our previous paper [12], we presented the use of sol-gel technique for the preparation of iridium oxide $\left(\mathrm{IrO}_{\mathrm{x}}\right) \mathrm{pH}$ sensing film on flexible Kapton substrate. The solid state $\mathrm{IrO}_{\mathrm{x}}$ film was formed by sol-gel technique, dip-coating [1,13], and thermal oxidation [14] processes.

Micro- and Nanotechnology: Materials, Processes, Packaging, and Systems IV edited by Jung-Chih Chiao, Alex J. Hariz, David V. Thiel, Changyi Yang, Proc. of SPIE Vol. 7269,726916 - (C) 2008 SPIE · CCC code: 0277-786X/08/\$18 - doi: 10.1117/12.810675 
In this paper, we presented the continuation of our previous work [12]. We demonstrated the repeatability, reproducibility, and stability of our $\mathrm{pH}$ sensor fabrication by the tests of linearity, time response, different volume, and step potential responses. The parameters including the metal thickness, sol-gel agent ratio, annealing temperature, and time of electro-plating on different fabrication batches were fixed in order to examine the repeatability and reproducibility of the fabrication process of our $\mathrm{pH}$ electrodes. Large- and small-volume tests demonstrated the stability of $\mathrm{pH}$ sensor performing in different environment condition.

The present paper showed the robust performance of our flexible $\mathrm{pH}$ sensor made by the simple $\mathrm{IrO}_{\mathrm{x}}$ solgel and $\mathrm{AgCl}$ electroplating methodology.

\section{SENSOR FABRICATION}

The $\mathrm{pH}$ sensor structures were formed on a flexible Kapton polyimide substrate. All metal layers were deposited by electron-beam evaporation. Photolithography and lift-off processes were applied in the fabrication procedures.

\section{Anodic Electrode Fabrication Procedure}

Metal deposition: A layer of 70- $\AA$ thick $\mathrm{Cr}$ was deposited as an adhesion layer of the $1000-\AA \AA$ thick Au layer as show in Fig.1 (a).

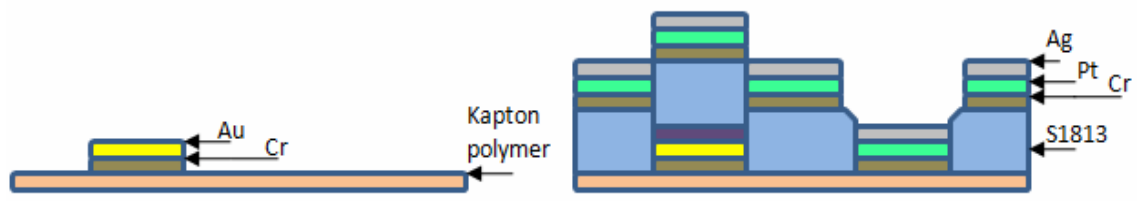

(a)

(d)

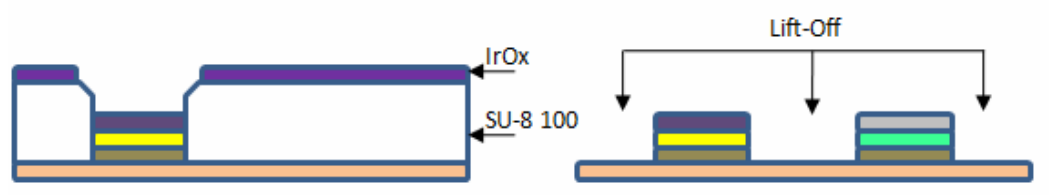

(b)

(e)

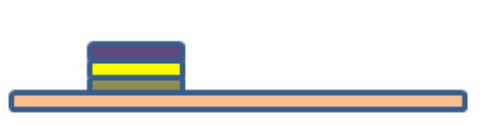

(c)

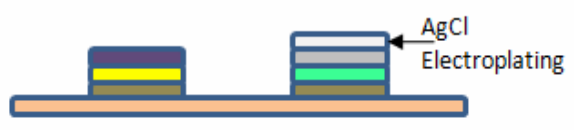

(f)

Figure 1 Fabrication processes: (a) $\mathrm{Cr}$ and Au deposition, (b) $\mathrm{IrCl}_{4}$ sol-gel process after $\mathrm{SU}-8$ deposition as the sacrificial layer, (c) lift-off process result, (d) Cr, Pt and Ag deposition with S1813 as the sacrificial layer, (e) lift-off process result, and (f) $\mathrm{AgCl}$ electroplating.

Sacrificial layer: A $100 \mu \mathrm{m}$ thick SU-8-100 photoresist layer was coated as shown Fig. 1(b) to be a sacrificial layer for $\mathrm{IrO}_{\mathrm{x}}$ sol-gel process. The SU-8 layer defined the sensing area on top of the Au layer. 
Ir $O_{x}$ sol-gel process: The sol-gel coating agent was based on the recipe described in [12,14]. The solution was stirred continuously for at least two hours with a magnetic rod. A thin layer on the flexible substrate was formed by dip coating at a $2 \mathrm{~cm} / \mathrm{min}$ withdraw rate by hand holding.

Thermal treatment: The sample was baked at $120^{\circ} \mathrm{C}$ for 15 minutes on a hot plate right after the dip coating process, and SU-8 layer was stripped off after baking. The sample was treated in an oven with a heating profile described in [12]. The surface needed to be treated at a temperature between $300^{\circ} \mathrm{C}$ and $350^{\circ} \mathrm{C}[15]$ to obtain an amorphous iridium oxide thin film.

\section{Cathode Electrode Fabrication Procedure}

Metal deposition: $70-\AA \AA$ thick Cr was deposited, followed by a $60-\AA \AA$ thick layer of $\mathrm{Pt}$ as an adhesion layer for the Ag layer. A 3000- $\AA$ thick Ag layer was deposited using the electro-plating process on top of the Pt layer as shown in Fig.1 (d).

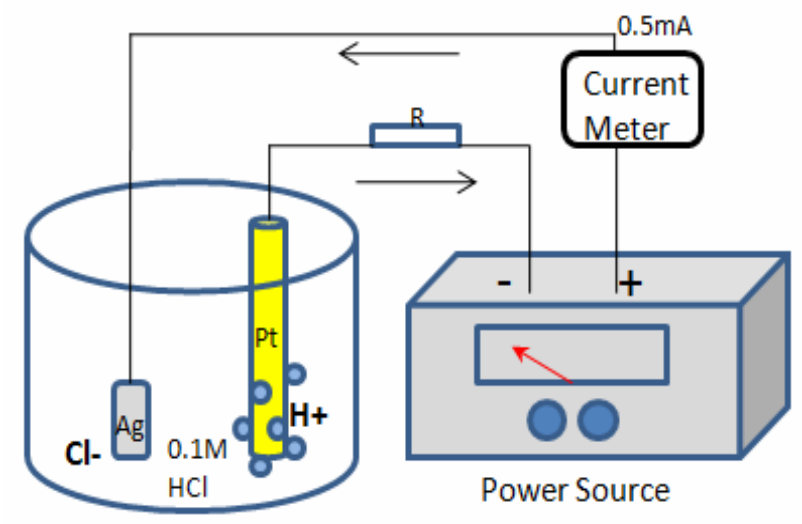

Figure 2 Electroplating setup for the $\mathrm{AgCl}$ reference electrodes.

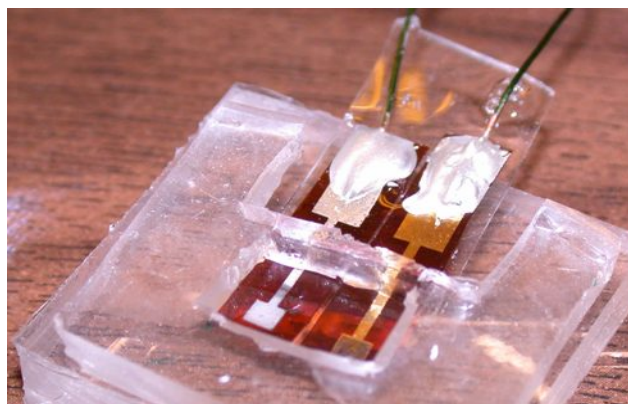

Figure 3 The PDMS polymer enclosure around the flexible $\mathrm{pH}$ sensor.

$\mathrm{AgCl}$ electro-plating: Electrochemical anodization process was used to obtain the silver chloride (AgCl) reference electrode same as the description in [12]. A brown silver chloride $(\mathrm{AgCl})$ layer was formed on the silver surface. The electrodes were saturated in potassium chloride $(\mathrm{KCl})[12,16]$. Fig. 2 shows the electroplating setup for the $\mathrm{AgCl}$ reference electrodes.

\section{PDMS Enclosure}

PDMS polymer was made in a 10:1 ratio by weight of SYLGARD 184 and curing agent [17]. The mix was cured on a $70^{\circ} \mathrm{C}$ hot plate for 24 hours. The $0.2-\mathrm{cm}$ thick PDMS layer was then bonded on the sensor surface with a well of $0.1 \mathrm{~cm}^{3}$ volume to confine $\mathrm{pH}$ buffer solution on the $\mathrm{pH}$ electrodes for measurements shown in Fig. 3 and Fig. 4 (b). 


\section{THEORY}

The iridium oxide $\left(\mathrm{IrO}_{\mathrm{x}}\right)$ and silver chloride $(\mathrm{AgCl})$ were used as sensing and reference electrodes, respectively. A pH-dependent redox equilibrium of two materials generated potential difference when $\mathrm{pH}$ was changed. There are three possible mechanisms on $\mathrm{pH}$-dependent redox equilibriums between two oxidation states of $\mathrm{IrO}_{\mathrm{x}}$. The $\mathrm{pH}$ potential sensitivity will be $-59.16 \mathrm{mV} / \mathrm{pH}$ regarded as the Nernstian potential response [18-20].

$$
\begin{aligned}
& \mathrm{Ir}_{2} \mathrm{O}_{3}+6 \mathrm{H}^{+}+6 e^{-} \leftrightarrow 2 \mathrm{Ir}+3 \mathrm{H}_{2} \mathrm{O} \\
& \mathrm{IrO}_{2}+4 \mathrm{H}^{+}+4 e^{-} \leftrightarrow \mathrm{Ir}+2 \mathrm{H}_{2} \mathrm{O} \\
& 2 \mathrm{IrO}_{2}+2 \mathrm{H}^{+}+2 e^{-} \leftrightarrow \mathrm{Ir}_{2} \mathrm{O}_{3}+\mathrm{H}_{2} \mathrm{O} \\
& E=E^{0}-2.303 \frac{\mathrm{RT}}{F} p H=E^{o}-59.16 p H
\end{aligned}
$$

\section{MEASUREMENTS}

In this paper, we aimed to demonstrate the repeatability of our $\mathrm{pH}$ sensors fabricated in different batches. Fig.4 (a) shows the measurement setup for our flexible pH sensors. An NI-DAQ 6008 USB card with a LabVIEW program was used for analog potential recording. A commercial Hanna $\mathrm{pH}$ meter was used to verify the $\mathrm{pH}$ values of solutions. The contact pads of the $\mathrm{pH}$ sensor were coated by silver epoxy in order to have good conductivity for the connection between the sensor and the DAQ card. A thin layer of PDMS was coated on top of the silver epoxy as shown in Fig. 3 for isolation when $\mathrm{pH}$ sensor was immersed in the test solution.

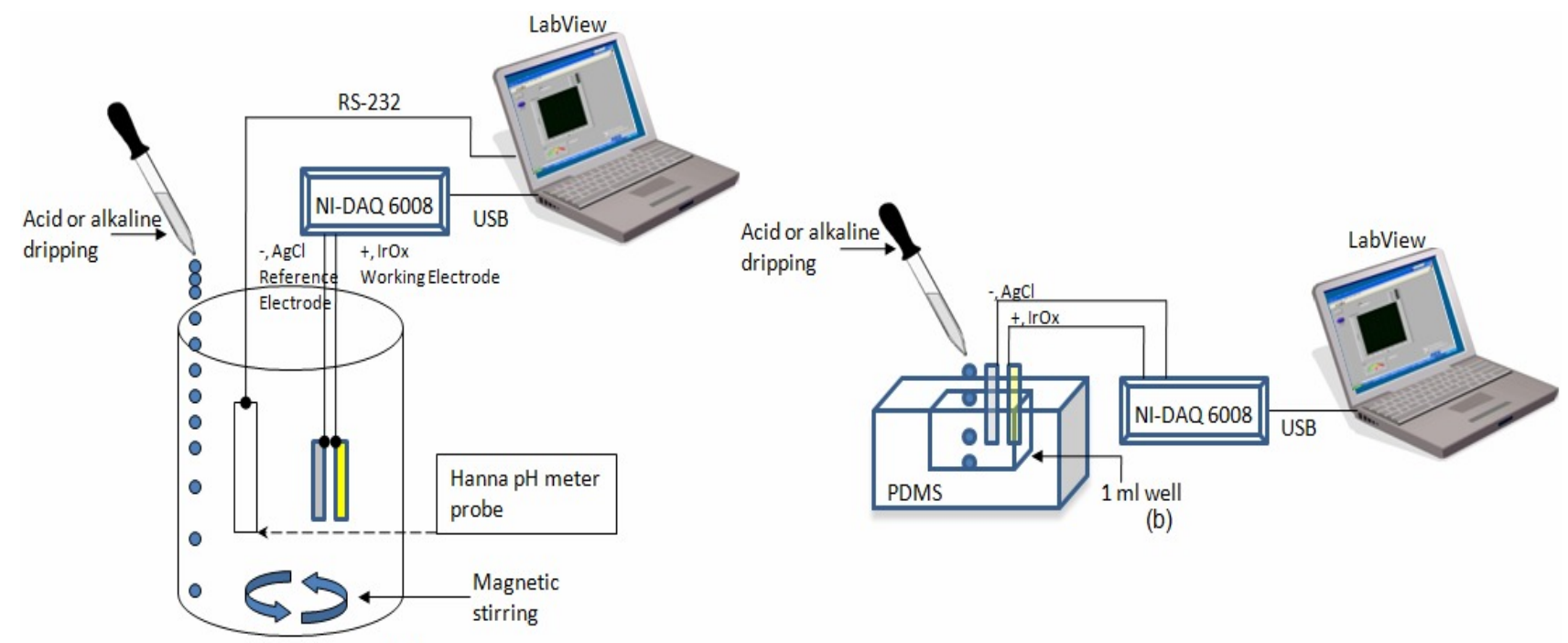

(a)

Figure 4 The $\mathrm{pH}$ titration and measurement setups for (a) large and (b) small volumes of solution. 
Titration test: The sensor was immersed in acid or alkaline based diluted solution stirred with a magnetic rod in the beaker. We used hydrochloric acid for acidic titration tests. $\mathrm{NH}_{3}$ and $\mathrm{KOH}$ were used for alkaline titration tests. The Hanna $\mathrm{pH}$ meter was placed in the solution and connected to its signal processing card. Both the potential from our sensor and the $\mathrm{pH}$ level from the Hanna $\mathrm{pH}$ meter were recorded in a computer simultaneously.

Small volume test: The $\mathrm{pH} \mathrm{2,} \mathrm{4,} \mathrm{6,} 10$ and 12 buffer solutions were dropped into the $0.1 \mathrm{ml}$ well individually to test the sensor performance. The sensor was rinsed by DI water between each test.

Large volume test: The sensor was immersed in $450 \mathrm{ml}$ of $\mathrm{pH} \mathrm{2,} \mathrm{4,} \mathrm{6,} 10$ and 12 buffer solutions individually in the beaker. The sensor was rinsed by DI water between each test.

\section{RESULTS AND DISCUSSION}

\section{Linearity Performance}

The reproducibility and repeatability of our fabrication process can be obtained by measuring three electrodes from different batches of identical fabrication process. Three linear potential responses of the three $\mathrm{IrO}_{\mathrm{x}} \mathrm{pH}$ sensors were confirmed by $\mathrm{pH}$ titration tests. $\mathrm{KOH}$ was dripped into diluted $\mathrm{HCl}$ based solution for titration. Shown in Fig. 5, the $\mathrm{pH}$ sensors from three different fabrication batches demonstrated near linear super-Nernstian responses [20] with similar sensitivities of $-71.6 \mathrm{mV} / \mathrm{pH},-81.7$ $\mathrm{mV} / \mathrm{pH}$ and $-110 \mathrm{mV} / \mathrm{pH}$ from $\mathrm{pH}=2$ to $\mathrm{pH}=12$ at $25^{\circ} \mathrm{C}$. The variances of these three linear responses were $0.032,0.018$, and 0.02 , respectively. These three sensors all performed better than the -59.16 $\mathrm{mV} / \mathrm{pH}$ super-Nernstian's sensitivity [18]. These sensitivity responses demonstrated good reproducibility in our fabrication process. The 10 to $30 \mathrm{mV}$ of sensitivity deviations between sensors may be due to different oxidation state as described in $[22,23]$.

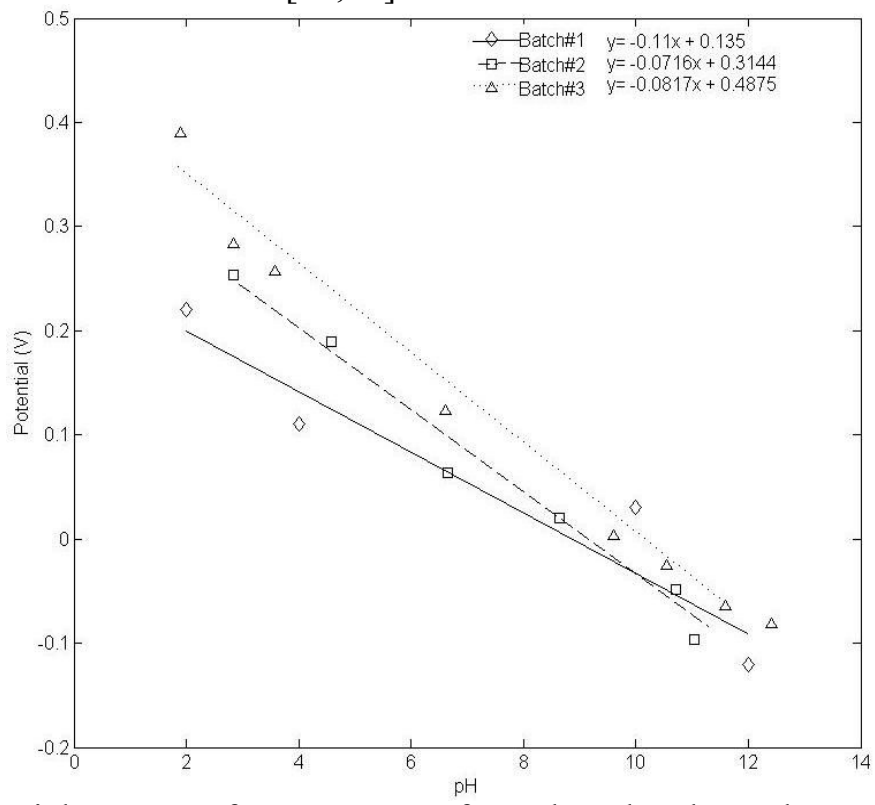

Figure 5 Linear potential response for $\mathrm{pH}$ sensors from three batches. The tested $\mathrm{pH}$ ranges from 2 to 12. 


\section{Response Time Performance}

Titration tests were performed to investigate the response time of our $\mathrm{pH}$ sensors. A rapid step change in $\mathrm{pH}$ level was represented by quickly adding a certain amount of $\mathrm{HCl}$ solution into alkaline-based solution or adding $\mathrm{KOH}$ solution into acidic solution. The response time is defined as the time required to reach $90 \%$ of the equilibrium value [21]. Fig. 6 shows the results of the $\mathrm{pH}$ sensors from three different fabrication batches with the transition steps of $\mathrm{pH}$ changing from $\mathrm{pH}=1.8$ to $\mathrm{pH}=8.4$ and from $\mathrm{pH}=5.6$ to $\mathrm{pH}=2.0$. The response times ranged from about 6 to 25 seconds, which also included and depended on the different mixing time of the dripped liquid with the base solution during titration processes. The localized mixing dynamics of liquid is difficult to control, however. These three sensors all showed similar and reasonable time responses during the titration, both from the acid to alkaline transition and alkaline to acid transition. This result not only presented good sensor reversibility, but also good reproducibility and repeatability.

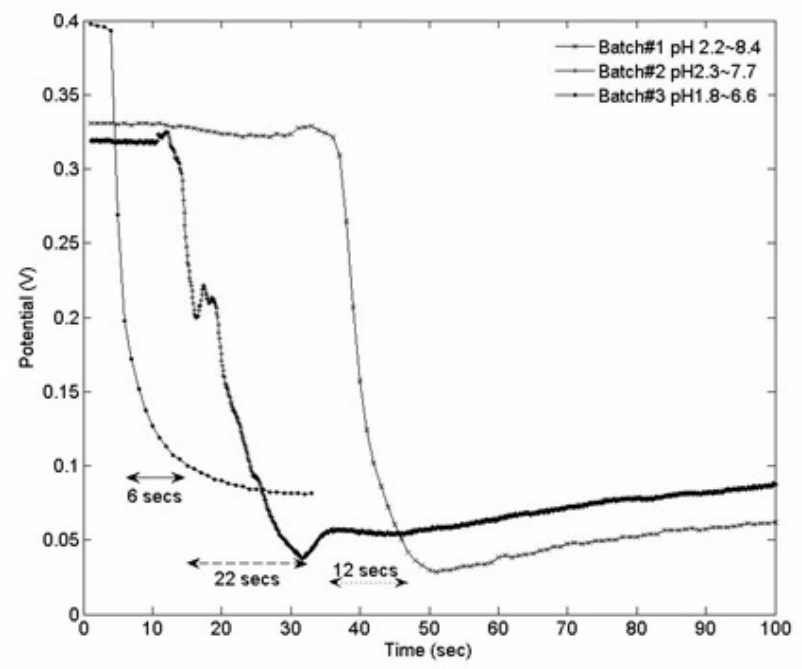

(a)

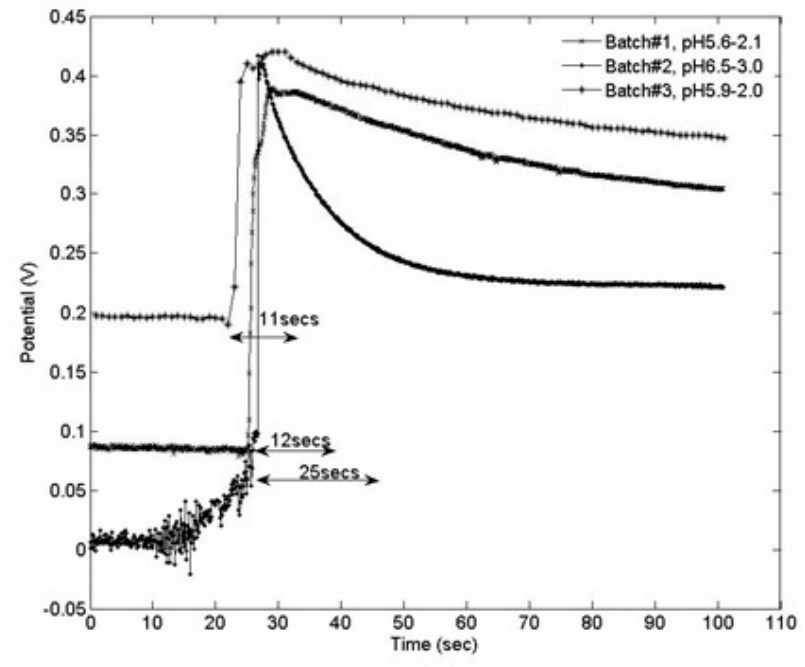

(b)

Figure 6 Response times of our $\mathrm{pH}$ sensors from (a) $\mathrm{pH}=1.8$ to $\mathrm{pH}=8$, and (b) $\mathrm{pH}=5.6$ to $\mathrm{pH}=2$.

\section{Environment Parameters}

Fig. 7 demonstrates the potential responses with two different volumes of $\mathrm{pH}$ buffer solutions for the $\mathrm{pH}$ sensors from three different fabrication batches. 0.1 and $450 \mathrm{ml} \mathrm{pH}$ buffer solutions were used as the small and large volumes. Three batches of the $\mathrm{pH}$ sensors showed close potential responses in the small volume tests of $\mathrm{pH}=2,4,6,10$ and 12 buffer solution. The $3^{\text {rd }}$ batch $\mathrm{pH}$ sensor was tested in the large volume $\mathrm{pH}$ buffer solutions. Both in small and large volume tests, the $\mathrm{pH}$ sensors showed similar linear responses and clear identification of different $\mathrm{pH}$ levels. In the experiment, the large volume of buffer solution produced higher potentials than the small volume buffer solution did at the same $\mathrm{pH}$ levels. This may be due to much more hydrogen ions in the large volume of liquid than in the small volume. With the mechanism of our $\mathrm{pH}$ sensor, the sensing potential depends on the $\mathrm{pH}$ value, which is the log value of the activity of the ion numbers. In this ion-selective $\mathrm{pH}$ sensor, it responds to the potential created or released 
by the active ions in the solution. Therefore, when the ion source is low, the potential will not reach the same level as the solution with higher ion strength does. The ion reduction also causes the result of slow response time resulting inaccurate $\mathrm{pH}$ measurements [24].

\section{Potential Step Responses}

Fig. 8 shows potential responses of two IrOx sensors to $\mathrm{pH}$ changes in a series of five different $\mathrm{pH}$ levels. The diluted HCl-based solution was titrated by $\mathrm{KOH}$ dripping from $\mathrm{pH}=1.8$ to $\mathrm{pH}=11.9$. Two sensing potentials responded to the $\mathrm{pH}$ level changes quickly when the titration started. This experiment demonstrated the dynamic testing of sensors from two different fabrication batches. The result showed that the response transients of two electrodes were almost identical with the titration steps. The deviation of potentials may be due to the oxide states as described in [23]. The higher potential responds to higher valence oxide and vice versa. The oxidation state is determined by the composition of IrOx film that can vary the potential shift at the same level of $\mathrm{pH}$ [23]. This experiment showed good stability of our sensors, and good reproducibility of the sol-gel fabrication processes.

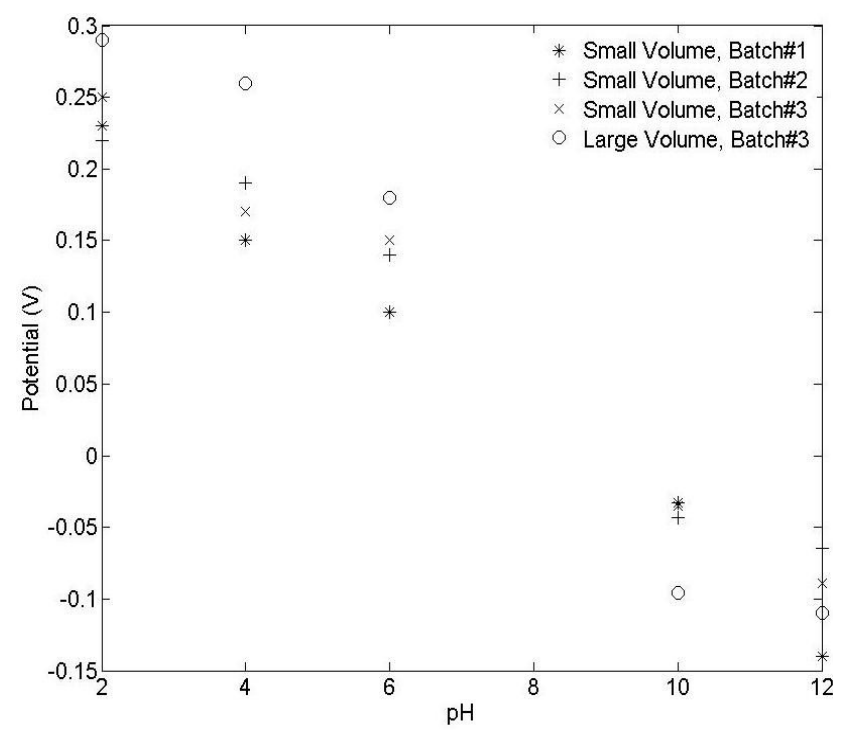

Figure 7 Large and small volume environment results.

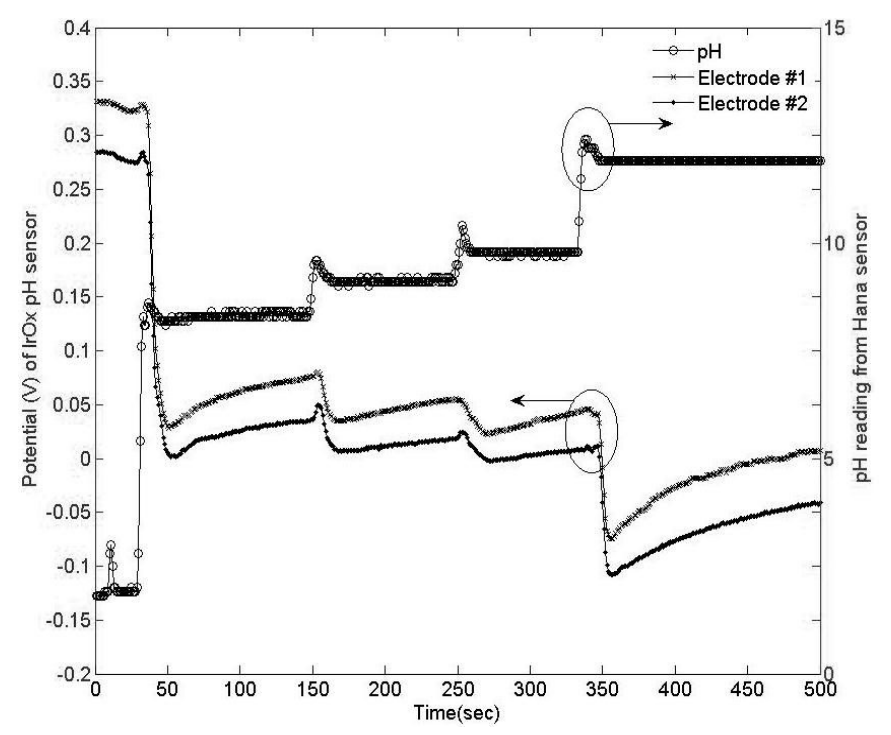

Figure 8 Potential responses in titration experiments.

\section{CONCLUSIONS}

This paper presented the repeatability, reproducibility, and stability of an $\mathrm{IrO}_{\mathrm{x}} \mathrm{pH}$ sensor fabricated on a flexible substrate. The sol-gel process was repeated in the different batches of fabrication process. Three different batches of $\mathrm{pH}$ sensors showed similar near super-Nernstian response which ranges from -71.6 $\mathrm{mV} / \mathrm{pH}$ to $-110 \mathrm{mV} / \mathrm{pH}$ as reproducible sensitivity in our fabrication process. These sensors demonstrated good reversibility, and similar response times to show the good reproducibility and repeatability in our fabrication process. Different volumes of fluid and step potential tests demonstrated good stability with three different batches of $\mathrm{pH}$ sensors. However, some potential deviations happened in the experiments. It 
may be due to the issues associated with the space charges, oxidation state, and film hydroxylation. Those phenomena maybe caused by the porous distribution, thickness, and surface properties of the $\mathrm{IrO}_{\mathrm{x}}$ thin film. With respect to the surface factors and different redox reactions occurred and related to changes of the $\mathrm{pH}$ charging potential, the fabrication quality control in the thickness and crystal structures of $\operatorname{IrO}_{\mathrm{x}}$ film is very important during the fabrication processes.

\section{ACKNOWLEDGEMENT}

The authors would like to express their sincere appreciation to US Air Force Office of Scientific Research for their financial support.

\section{REFERENCES}

[1] H. Galster, pH measurements-fundamentals, methods, applications, instruments, VCH publishers, New York, 1991.

[2] Yi Liu, Tianhoung Cui, "Ion-sensitive field-effect transistor based $\mathrm{pH}$ sensors using nano selfassembled polyelectrolyte/nanoparticle multilayer films," Sensors and Actuators B, Vol. 123, pp. 148-152, Aug. 2.006.

[3] Jinghong Han, Dafu Cui, Yating Li, et al., "A gastroesophageal tract pH sensor based on the HISFET and the monitoring system for 24 h," Sensors and Actuators B, Vol. 66, pp. 203-204, July 2000.

[4] Otto S. Wolfbeis, "Fiber-optic chemical sensors and biosensors," Anal. Chem., Vol. 76, pp. 32693284, 2004.

[5] Saying Dong, Ming Luo, Gangding Peng, and Wenhua Cheng, "Broad range pH sensor based on solgel entrapped indicators on fiber optic," Sensors and Actuators B: Chemical, Vol. 129, pp. 94-98, Jan. 2008.

[6] Gerald Gerlach, Margarita Guenther, et. al, "Chemical and $\mathrm{pH}$ sensors based on the swelling behavior of hydrogels," Sensors and Actuators B, Vol. 111-112, pp. 555-561, Nov. 2005.

[7] Agner Fog, Richard P. Buck, "Electronic semiconducting oxides as pH sensors," Sensors and Actuators, Vol. 6, pp. 137-146, 1984.

[8] Patrick J. Kinlen, John E. Heider, and David E. Hubbard, "A solid-state pH sensor based on a Nafioncoated iridium oxide indicator electrode and a polymer-based silver chloride reference electrode," Sensors and Actuators B, Vol. 22, pp. 13-25, 1994.

[9] Roy Biran, David C. Martin and Patrick A. Tresco, "Neuronal cell loss accompanies the brain tissue response to chronically implanted silicon microelectrode arrays," Experimental Neurology, Vol. 195, pp. 115-126, 2005.

[10] Vadim S. Polikov, Patrick A. Tresco and William M. Reichert, "Response of brain tissue to chronically implanted neural electrodes," Journal of Neuroscience Methods, Vol. 148: pp.1-18, 2005.

[11] Jianqun Wang, Ying Cai, Thermpon Ativanichayaphong, Mu Chiao and J.-C. Chiao, "Fabrication techniques for RF transmission lines on polymer substrates," Microelectronics, MEMS, and Nanotechnology Symposium, Microelectronics: Design, Technology, and Packaging Conference, Brisbane Australia, Dec. 11-14, 2005.

[12] Wen-Ding Huang, Jianqun Wang, Thermpon Ativanichayaphong, Mu Chiao and J.C. Chiao, "Development of an IrOx Micro pH Sensor Array on Flexible Polymer Substrate," SPIE Nanosensors and Microsensors for Bio-Systems Conference, San Diego, March 9-13, Vol. 6931, 693104, 2008. 
[13] C. Jefferey Brinker, George W. Scherer, Sol-Gel Science: The physics and Chemistry of Sol-Gel Processing, pp.788-798, Academic Press, Boston, 1990.

[14] K. Nishio, Y. Watanabe, T. Tsuchiya, "Preparation and properties of electrochromic iridium oxide thin film by sol-gel process," Thin Solid Films, Vol. 350, pp. 96-100, 1999.

[15] Akiyoshi Osaka, Toru Takatsuna, Yoshinari Miura, "Iridium oxide films via sol-gel processing," Non-Crystalline Solids, Vol. 178, pp. 313-319, 1994.

[16] A W J Cranny, J K Atkinson, "Thick film silver-silver chloride reference electrodes," Meas. Sci. Technol, pp.1557-1565, 1998.

[17] Xin Q. Brown, Keiko Ookawa, and Joyce Y. Wong, "Evaluation of polydimethylsiloxane scaffolds with physiologically relevant elastic moduli: interplay of substrate mechanics and surface chemistry effects on vascular smooth muscle cell response," Biomaterials, Vol. 26, pp. 3123-3129, 2005.

[18] M. Pourbaix, "Atlas of electrochemical equilibria in aqueous solutions," National Association of Corrosion Engineers, pp. 374-377, 1974.

[19] Sheng Yao, Min Wang, and Marc Madou, "A pH electrode based on melt-oxidized iridium oxide," Journal of the elecvtrochemical society, Vol. 148, pp. 29-36, 2001.

[20] Erno Pungor, "The theory of ion-selective electrodes," The Japan society for analytical chemistry, Vol. 14, pp. 249-256, 1998.

[21] Haley R. Clark, Timothy A. Barbari, "Modeling the response time of an in vivo glucose affinity sensor," Biotechnol. Prog., Vol. 15, pp. 259-266, 1999.

[22] Santi Chrisanti, "A pH electrode based on melt-oxidized iridium oxide," Master Degree Thesis, Ohio State University, pp. 25-26, 2003.

[23] W. Olthuis, M. A. M. Robben, P. Bergveld, M. Bos and, W. E. van der Linden, "pH sensor properties of electrochemically grown iridium oxide," Sensor and Actuators B, Vol. 2, pp. 247-256, 1990.

[24] Reagecon Technical Report, "The Theory of pH Measurement," pp.8-9, http://www.reagecon.com/TechPapers/phfaqv4.pdf. 